\title{
Representação da informação e Ecomuseu: interdisciplinaridade entre Ciência da Informação e Museologia
}

\section{Leonardo Hermes Lemos}

Cezar Karpinski ${ }^{I I}$

https://orcid.org/0000-0003-2446-0653

I Universidade Federal de Santa Catarina, SC, Brasil.

Doutorando em Ciência da Informação.

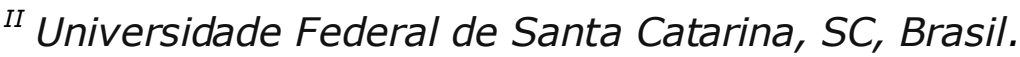

Docente no Departamento de Ciência da Informação.

http://dx.doi.org/10.1590/1981-5344/3722

Este trabalho tem como tema a representação da informação em ecomuseu, uma categoria específica de instituição museológica criada a partir da década de 1970. A pesquisa se ateve a dois ecomuseus no Estado de Santa Catarina e teve como objetivo pesquisar as formas de representação da informação destes ecomuseus. Do ponto de vista metodológico a pesquisa se classifica como aplicada, qualitativa e exploratória. Os procedimentos técnicos adotados foram a pesquisa bibliográfica e a pesquisa de campo, a primeira em seis bases de dados e a segunda desenvolvida a partir de estudo de caso, observação e história oral.Como resultados verificou-se que as formas de representação da informação nas duas instituições são a documentação em museus, a exposição e a mediação. Como conclusão, ressalta-se a importância do caráter interdisciplinar da Ciência da Informação e da Museologia, mostrando as possibilidades de pesquisas 
conjuntas entre ambas, promovendo o desenvolvimento prático e teórico das duas áreas do conhecimento.

Palavras-chave:Ciência da Informação;representação da Informação; Ecomuseu; Museologia; Ecomuseologia.

\section{Information representation and Ecomuseum: interdisciplinary between Information Science and Museology}

This work has as its theme the representation of information in ecomuseum, a specific category of museological institution created in the 1970s. The research was carried out in two ecomuseums in the State of Santa Catarina and aimed to research the forms of information representation of these ecomuseums. From a methodological point of view, the research is classified as applied, qualitative and exploratory. The technical procedures adopted were bibliographic research and field research, the first in six databases and the second developed from case study, observation and oral history. As a result, it was found that the forms of information representation in the two institutions are documentation in museums, exhibition and mediation. In conclusion, it stands out the importance of the interdisciplinary of Information Science and Museology, showing the possibilities of research between both, promoting the practical and theoretical development of the two areas of knowledge.

Key-words: Information Science; information representation; Ecomuseum; Museology; Ecomuseology.

Recebido em 09.10.2018. Aceito em 04.06.2020 


\section{Introdução}

São inúmeras as aproximações da Ciência da Informação com a Museologia, pois o escopo de várias pesquisas dos dois campos de conhecimento assemelha-se ou tem vertentes teórico-metodológicas comuns. De acordo com Araújo (2014), uma destas possibilidades é a representação da informação que visa descrever o conteúdo informacional dos documentos, entendidos na Museologia como objetos museais. A referência do objeto museal como documentos e faz presente já em Otlet (1934), quando este considerou itens tridimensionais como portadores de informação, podendo ser classificadostambém como documentos. Ainda segundo Otlet (1934), os objetos como documentos poderiam ser divididos em cinco categorias sendo: 1) objetos naturais; 2) objetos artificiais; 3) objetos com traços humanos; 4) objetos demonstrativos; e 5) objetos de arte.

Assim, entende-se que a instituição de guarda documental, ao constituir padrões de representação da informação, facilita a recuperação dos dados e, consequentemente, o acesso à informação para qualquer tipo de usuário.Especificamente na Museologia, a representação da informação pode acontecer por meio de processos técnicos variados e de acordo com cada categoria de Museu. Este relato de experiência mostra como dois ecomuseus no Estado de Santa Catarina representam a informação. A escolha pelo ecomuseu se deve ao fato de ser uma instituição museal criada a partir da década de 1970 e por relacionar, na mesma unidade de informação, o patrimônio cultural, o seu território eacomunidade local.

Nesse sentido, as questões que nortearam a pesquisa foram: quais as formas de representação da informação nos ecomuseus, e como esta prática contribui para as discussões que visam aproximara Ciência da Informação e a Museologia. O objetivo foi pesquisar as formas de representação da informação em ecomuseus identificando, no escopo geral do tratamento museológico das instituições analisadas, quais procedimentos podem ser considerados representação da informação.

Este relato de experiência está dividido em três partes, sendo a primeira uma breve contextualização histórica sobre a criação do ecomuseu enquanto conceito e instituição museológica, além de apresentar as duas instituições pesquisadas: Ecomuseu Dr. Agobar Fagundes (EDAF), de Blumenau-SC, e Ecomuseu do Ribeirão da Ilha, de Florianópolis-SC. Asegunda parte explica as metodologias adotadas (história oral e pesquisa de campo) e seus resultados. Por fim serão expostas as contribuições do trabalho para o fomento das relações interdisciplinares entre a Ciência da Informação e a Museologia a partir dos resultados da pesquisa. 
O principal resultado da pesquisa éa constatação de que as formas de representação da informação presentes nos ecomuseus em questão são a documentação em museu, a exposição e a mediação. A primeira por detalhar o conteúdo informacional dos objetos museais, a segunda por ser o principal canal de acesso a estas informações, e a terceira por possibilitar informações adicionais ao público das instituições.

\section{Ecomuseu: definição, contexto histórico e apresentação do estudo de caso}

O processo histórico de criação do ecomuseu enquanto categoria museal, bem como seu conceito, nasceu na década de 1970. Segundo Brulon (2015), o ecomuseu surgiu com a criação do Écomusé e Du Creusot Montceau-Les-Mines (França), idealizado por Marcel Evrard. A criação desta nova categoria de museu advém de um movimento de reflexão e crítica aos modelos obedientes à uma "Museologia Tradicional". ${ }^{1}$ Isto porque 0 ecomuseu busca relacionar o patrimônio cultural com o território em que está inserido, o que difere, em termos conceituais e pragmáticos, da proposta dos Museus Nacionais, voltada à constituição e preservação do patrimônio cultural de uma nação.

Chagas (2000) explica que o museu tradicional tem como foco os objetos, um prédio físico e um público específico, enquanto o ecomuseu busca relacionar as formas de patrimônio cultural de determinado território, a modificação deste pela ação humana e como ele interage com a comunidade. A noção de território, neste caso, pressupõe o meio ambiente que integra o ecomuseu, fazendo parte deste espaço as características físicas (paisagem), a fauna, a flora e a comunidade humana. Nesse sentido, o conceito de território é essencial para a constituição do Ecomuseu, uma vez que engloba aspectos naturais e culturais na construção da sua coleção ou objetos museais, tendo vínculos estreitos com as noções de Patrimônio em suas interfaces Cultural, Material, Natural e Imaterial. ${ }^{2}$

Um dos principais autores a conceituar o ecomuseu como uma nova categoria de museu é Varine (1985) que, ao defender a abertura dos museus para a sociedade, estabeleceu o conceito de ecomuseu e

1Por Museologia Tradicional a bibliografia da área tem denominado os museus que possuem estreita relação com seu acervo, espaço construído e patrimônio material. Estas definições estão presentes em algumas obras da área entre elas Botallo (1995) ePoulot (2013).

2Sobre o conceito de território nesta perspectiva ver Roncayolo (1986). Para uma discussão abrangente acerca do conceito de Patrimônio que serviu de pressuposto para esta pesquisa ver Choay (2014) e Chagas e Abreu (2009). 
ecomuseologia.Mesmo o conceito sendo definido na década de 1970, Scheiner (2012) enfatiza que os ecomuseus tiveram grande influência dos museus a céu aberto, já constituídos em alguns países da Europa desde a década de 1950.

No mesmo contexto, pode-se afirmar que a emergência e a importância do ecomuseu para a Museologia se devem também às discussões anteriores sobre o papel educacional das instituições museológicas, iniciadas na década de 1950. Esse debate foi embasado pelos ideais de Paulo Freire que, de acordo com Querol (2013), foram cruciais para a realização do "Seminário Regional da UNESCO sobre o Papel Pedagógico dos Museus", ocorrido no Brasil em 1958.

Enquanto instituição, o ecomuseu se reforça também a partir doconceito de museu integral, instaurado no ano de 1972 na Carta de Santiago do Chile. Scheiner (2012) expõe que, desde a década de 1950, o papel social do museu vinha sendo discutido, principalmente no cenário posterior à segunda guerra mundial. A mesma estudiosa salienta que 0 conceito de museu integral contribuiu para as reflexões sobre a Museologia a partir de um documento referencial, a Carta de Santiago do Chile. Consequentemente, esse debate potencializou a discussão acerca da importância social dos museus na América Latina.

Ainda de forma contextual, é possível afirmar que oecomuseu foi uma instituição museológica importante para o desenvolvimento do se convencionou denominar "Movimento por uma Nova Museologia (MINOM)"no ano de 1984. Este movimento propôs que o público se tornasse um sujeito ativo no museu e, com esta perspectiva,constituiu-se a "Nova Museologia", corrente epistemológica que busca fortalecer o papel social dos museus. Esse novo entendimento se fortaleceu a ponto do constituir um dos movimentos mais importantes da área de Museologia, fazendo-se presente hoje no próprio International Council of Museums (ICOM).

\subsection{O Ecomuseu Dr. Agobar Fagundes (EDAF), Ecomuseu do Ribeirão da Ilha e a representação da informação.}

O EDAF está localizado na comunidade rural da Nova Rússia, Blumenau, Santa Catarina, Brasil. Criado no ano de 2007 pela Profa. Dra. Valda de Oliveira Fagundes, a instituição homenageia seu falecido esposo. Além disto, o EDAF desenvolve pesquisas e trabalhos relacionando meio ambiente, território e comunidade. Exemplos de trabalhos desenvolvidos pela instituição são: levantamento da mastofauna da região; cultura e ruralidade; escoteirismo; entre outros. A instituição possui uma área expositiva (Figura 1 e figura 2), um auditório (em construção), uma biblioteca e trilhas ecológicas. 
Figura 1 - Exposição de longa duração

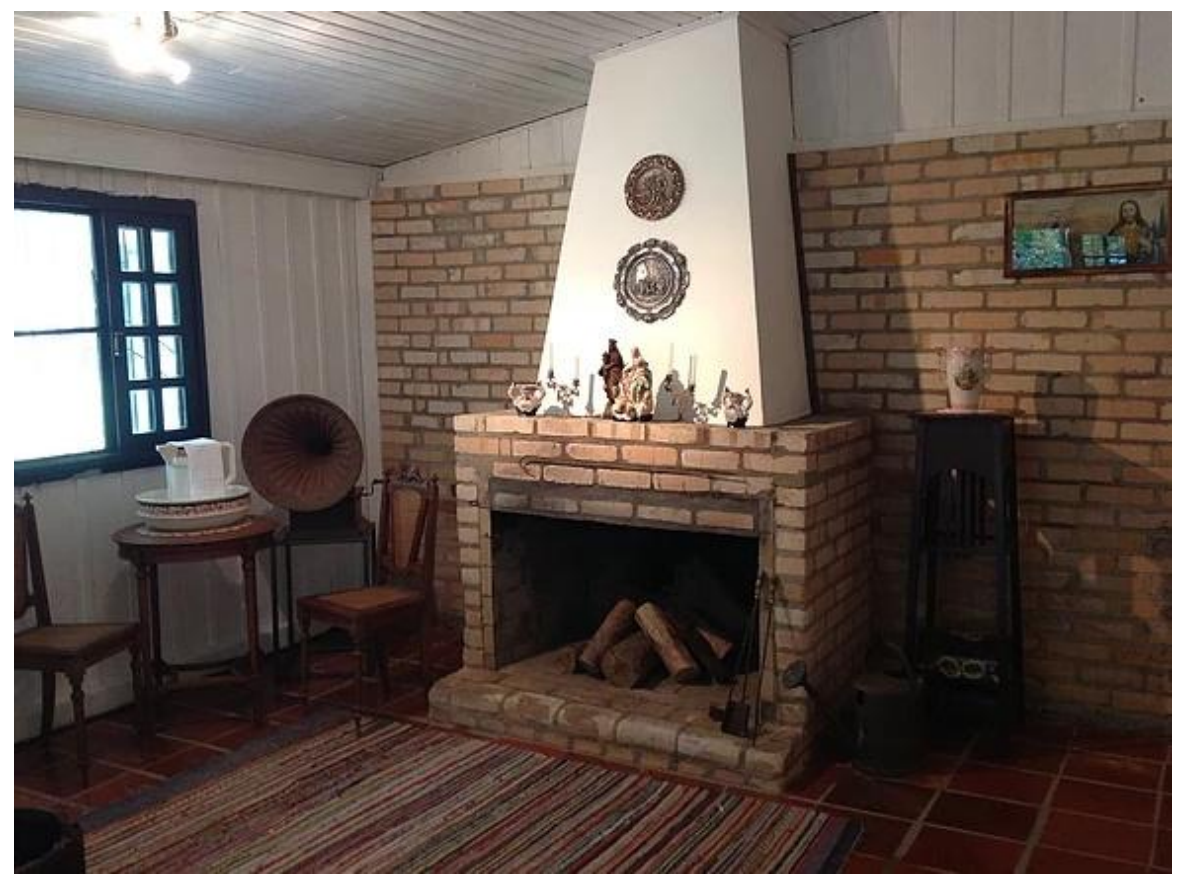

Fonte: Ecomuseu Dr. Agobar Fagundes (2016a)

Figura 2 - Exposição de longa duração

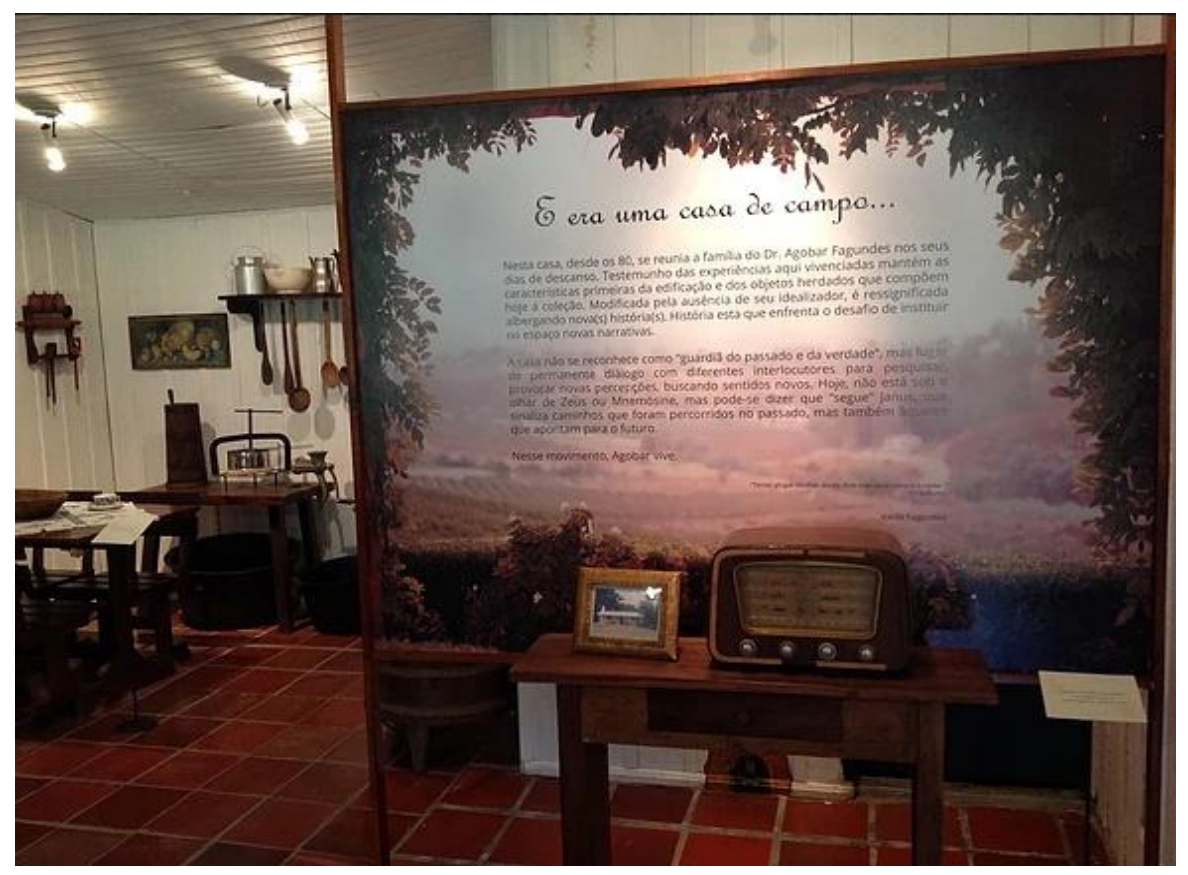

Fonte: Ecomuseu Dr. Agobar Fagundes (2016b) 
Por sua vez, o Ecomuseu do Ribeirão da Ilha está localizado no distrito do Ribeirão da Ilha, Florianópolis, Santa Catarina, Brasil. Criado em 2007 pelo Prof. Nereu do Vale Pereira, a instituição contextualiza a forma como os colonizadores açorianos viviam no litoral catarinense, especificamente naquela região. O ecomuseu em questão possui: um auditório onde é apresentada ao visitante a cronologia histórica da formação do distrito do Ribeirão da Ilha e de Florianópolis; uma casa do início do século XX (Figura 3) onde estão expostos objetos do cotidiano dos colonos açorianos; e um engenho de farinha de mandioca (Figura 4) mostrando uma das principais culturas de alimentação e comércio dos colonizadores.

Figura 3 - Casa em estilo Açoriano

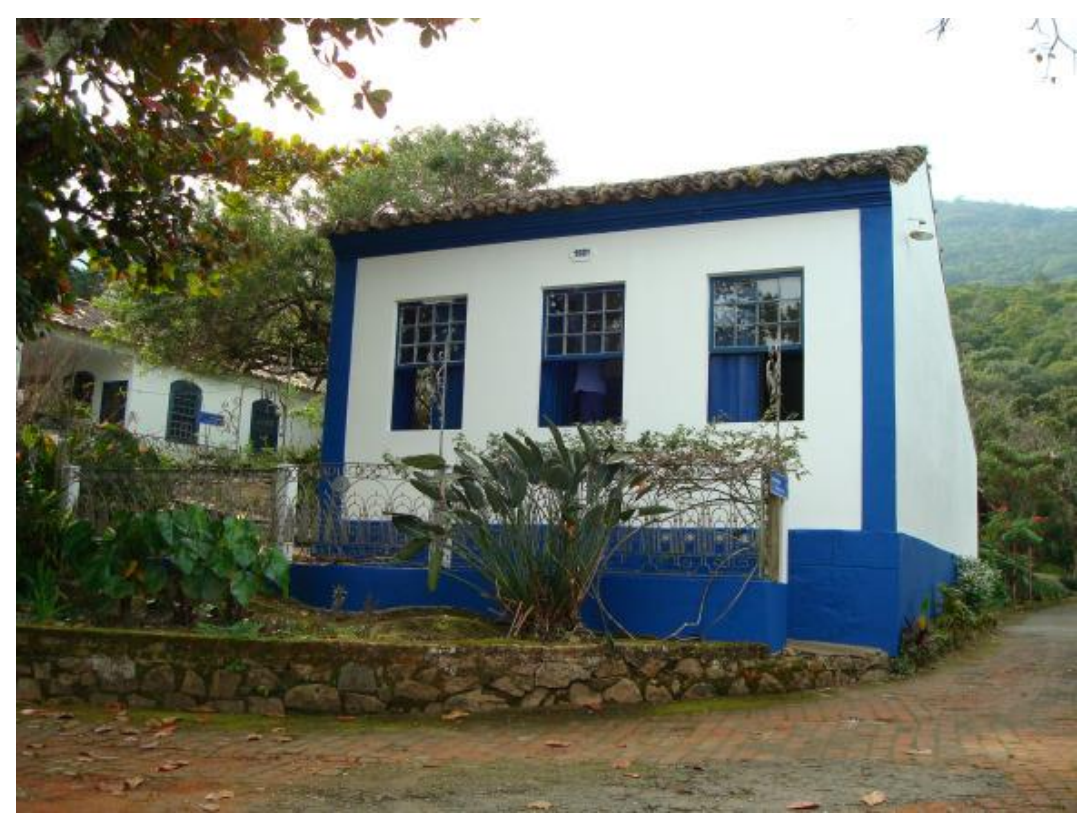

Fonte: Ecomuseu do Ribeirão da Ilha (2011a) 
Figura 4- Engenho de farinha de mandioca

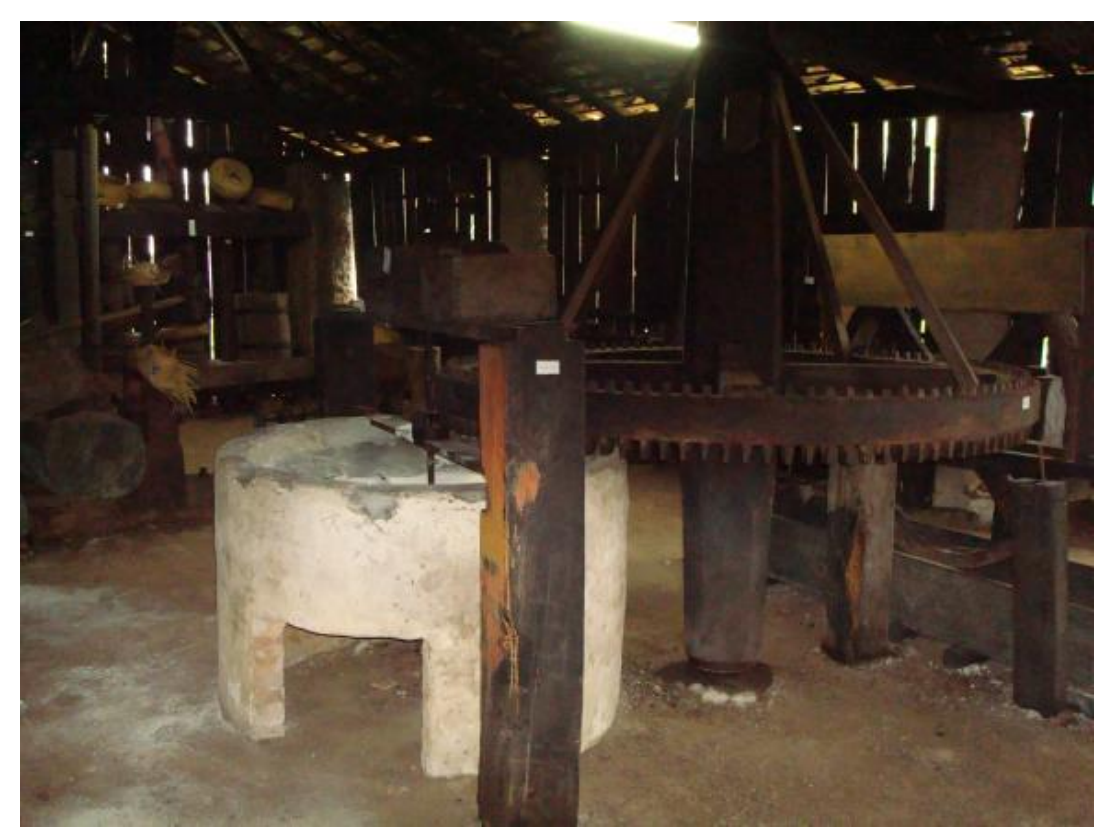

Fonte: Ecomuseu do Ribeirão da Iha (2011b)

Ambos os ecomuseus são considerados, neste artigo, Unidades de Informação, pois organizam, recuperam e possibilitam o acesso a informação. Nesse sentido, um dos mecanismos facilitadores é a representação da informação, por ser um ponto de interconexão entre os processos desenvolvidos no ecomuseu com a Ciência da Informação. Por representação da informação, entende-se o que Brascher e Café (2008) definem: amaneira pela qual as informações de um documento são descritas. Essas autoras, para conceituarem a representação da informação, diferem os conceitos de informação e conhecimento, o que algumas vezes ainda é confundido na própria área da Ciência da Informação. Como características de informação enfatizam os pontos definidos por Fogl (1979), mostrando que o conhecimento é um processo cognitivo humano e a informação seria a materialização deste conhecimento.

Portanto, a opção por utilizar apenas a representação da informação e não a representação do conhecimento, nesta pesquisa, está vinculada ao fato de identificar e analisar as características da informação, na área da Museologia, especificamente na forma como as informações são representadas nos ecomuseus. Ressaltando de forma sucinta as diferenças entre informação e conhecimento, isto se relaciona com a área museológica por evidenciar os objetos museais também como documentos, o que já foi destacado anteriormente. Brascher e Café (2008) ressaltam que a representação da informação é o resultado da organização da informação, e que podem existir diferentes processos de 
representação, como: catalogação, indexação, entre outras formas que descrevam as informações dos documentos.

Por meio da representação da informação é possível verificar a relação entre Ciência da Informação e Museologia, enquanto áreas interdisciplinares, o que é mostrado por Araújo (2014) que explora os pontos de intersecção das áreas. O autor destaca que arepresentação da informação possibilita a recuperação e acesso a informação de documentos, sendo um dos pontos de aproximação de ambas as áreas, sendo uma temática necessária em estudos como o que se apresenta aqui.

\section{Procedimentos metodológicos}

Do ponto de vista metodológico a pesquisa se classifica como aplicada, quanto à sua natureza, qualitativa, no caráter de sua abordagem, e exploratória, quanto aos seus objetivos.No tocante aos procedimentos técnicos, foram desenvolvidas a pesquisa bibliográfica e a pesquisa de campo. (LIRA, 2014; GIL, 2010).

A pesquisa bibliográfica se deu por meio de um levantamento da produção científica sobre o tema, principais autores e assuntos relacionados à representação da informação, Museologia e Ecomuseologia. Foram consultadas seis bases de dados (EBSCO, Emerald Insight, Science Direct, SCOPUS, ProQuest e WEB of Science) e uma biblioteca digital (SciELO).Os motivos de escolha dessas fontes de pesquisa foram: possibilidade de importação de arquivos para o Software EndNote; indexadores de revistas Qualis A1 e A2 da área de Comunicação e Informação; possibilidade de acesso via VPN pela Universidade Federal de Santa Catarina.

Para a realização do levantamento bibliográfico foram definidas vinte e cinco chaves de busca, relacionando cinco palavras-chaves, sendo: Ciência da Informação, Representação da Informação, Museologia, Ecomuseu e Ecomuseologia. Como filtros de busca foram definidos: 1) Acesso aberto; 2) Recorte temporal (entre 01 de janeiro de 2008 a 06 de junho de 2017); 3) Artigos; 4) Idioma (inglês, espanhol e português); e 5) Área do conhecimento (Comunicação e Informação e/ou Ciências Sociais Aplicadas II). Após isto, os trabalhos recuperados foram anexados no Software End Note para fins de gerenciamento (exclusão de duplicada e classificação de relevância). O corpus documental selecionado contribuiu para o desenvolvimento da pesquisa de campo e os resultados das análises a essa produção científica são apresentados por Lemos e Karpinski (2019).

Já a pesquisa de campo foi realizada nas duas instituições pesquisadas e abrangeu três procedimentos metodológicos: Estudo de caso; Observação; História oral. Conforme Cruz Neto (2001) por meio da 
pesquisa de campo é possível que o pesquisador tenha maior contato com seu objeto de estudo, onde as investigações que são feitas possuem respostas que se interligam possibilitando a constituição de conhecimento e alcance dos objetivos.

O estudo de caso foi realizado nos moldes apresentados por Triviños (1987) que resume esta técnica como uma categoria de pesquisa que analisa profundamente uma determinada realidade, neste caso, os ecomuseus como unidade de informação. Como consequência deste procedimento, a pesquisa adotou também a observação que, como Cruz Neto (2001) e Lakatos e Marconi (2012) enfatizam, possibilita ao pesquisador integrar-se a determinado grupo para a coleta de informações relevantes para o alcance de seus objetivos. Os dados advindos da observação foram anotados em um diário de campo que serviu posteriormente para a análise das informações advindas da história oral.

Ainda como pesquisa de campo, utilizou-se a metodologia da história oral. Inicialmente utilizada por historiadoresno século $X X$, a metodologia da história oral se difundiu sobremaneira nas pesquisas sociais aplicadas e foi um instrumento de grande utilidade nesta pesquisa. De acordo com Alberti (1996), a história oral possibilita a reflexão sobre as experiências dos sujeitos da pesquisa, por meio da constituição de fontes de informação oral. Por meio de entrevistas gravadas em áudio ou áudio e vídeo, os atores sociais pesquisados discorrem sobre os seus feitos do passado a partir dos dispositivos da memória (MONTYSUMA, 2006).

Para elaboração das entrevistas, seguiram-se as recomendações de Karpinski e Montysuma (2009) com a escolha de entrevista temática, elaboração do roteiro com perguntas previstas, gravação apenas do áudiopor meio de aplicativo de gravação em smartphone e posterior transcrição do conteúdo. As perguntas foram abertas e tiveram como pontos principais: 1) criação e contexto de fundação das instituições; 2) equipe das instituições; 3) ações desenvolvidas; e 4) relação do ecomuseu com a comunidade.

A primeira entrevista foi realizada com Profa. Dra. Valda de Oliveira Fagundes, diretora e fundadora do EDAF, doravante citada por Fagundes (2017), no dia 15 de março de 2017. O local de gravação foi a própria sede do EDAF e durou cerca de 47 minutos. As entrevistas sobre o Ecomuseu do Ribeirão da Ilha foram fornecidas por Cristina Maria Dallanora e Prof. Nereu do Vale Pereira, no dia 11 de abril de 2017, na sede do mesmo ecomuseu, durando 32 minutos (entrevista de Cristina Maria Dallanora) e 52 minutos (entrevista de Prof. Nereu do Vale Pereira), doravante citados por Dallanora (2017) e Pereira (2017), respectivamente. 
As três entrevistas estão salvas em serviço de armazenamento virtual (Google Drive) e ambos os entrevistados concordaram com a utilização das informações das entrevistas, mediante a assinatura do Termo de Consentimento Livre e Esclarecido (TLCE), da Universidade Federal de Santa Catarina (UFSC), obedecendo aos critérios éticos da pesquisa e da metodologia.Também foi autorizada a utilização dos nomes próprios. Ainda no aspecto ético, a pesquisa seguiu os protocolos da metodologia da história oral nos termos de Perelmetter e Antonacci (1997) Portelli (1997), Pozzi (2014).

\section{Documentação em museu, exposição e mediação}

Uma das técnicas museológicas que contempla a representação da informação é a documentação em museu, prática corrente em todos os tipos de instituições museológicas. No estudo de caso, foi verificado que o Ecomuseu do Ribeirão da Ilha contempla este procedimento, enquanto que, no EDAF, este processo é ausente. Porém,a documentação em museu no EDAF consta no plano museológico da instituição, onde está prevista a sua execução.

Segundo Mensch (1992), a documentação em museu é a forma mais comum de pesquisar, coletar e descrever as informações dos objetos, por meio de suas características intrínsecas e extrínsecas. Dessa forma, podese considerar a documentação em museu como uma forma de representação da informação na Museologia. É por meio deste processo que seanalisa de forma sistemática o conteúdo informacional dos objetos museais. Contudo,no ecomuseu, a informação ultrapassa a materialidade do objeto, pois a instituição congrega ainda a relação do objeto com o patrimônio cultural, com o território e com a comunidade. Desta maneira, outras duas formas de representação da informação foram identificadas no estudo: a exposição e a mediação.

Sobre a exposição, Cunha (2005) explica que esta é a melhor forma de extroversão das informações dos objetos museológicos que são contextualizados em discurso ou narrativa. Assim, por meio deste processo,o público do museu acessa as informações constantes nos objetos museais, a partir do contexto e da narrativa constituídos pela instituição. Sendo assim, os elementos que formam uma exposição e que a caracterizam como representação da informação nas instituições pesquisadas foram: os textos explicativos; as etiquetas; o percurso e a narrativa que a exposição possui.

O EDAF, por exemplo, possui uma exposição intitulada, 'Novas Fronteiras entre Museu, Territórios e Culturas', com textos explicativos sobre cada módulo, atribuindo as características da modificação da paisagem cultural pela sociedade humana. Já no início do percurso se apresenta a proposta da exposição e, posteriormente, expõem-se objetos 
que representam a cultura das populações indígenas, considerando-os como os primeiros habitantes daquele território. Seguindo este percurso ecomuseológico, a exposição se concentra na colonização europeia da região e finaliza com um memorial ao Dr. Agobar Fagundes, mostrando como a antiga casa de campo da família se tornou no EDAF.

Esta exposição do EDAF é auxiliada por etiquetas explicativas em determinados objetos e também textos adicionais sobre os módulos em três idiomas: português, espanhol e inglês. Com relação ao percurso, existe uma ordem a ser seguida para entender a proposta do EDAF que é pesquisar, estudar e expor objetos, pesquisa e outros elementos que contribuam com os projetos da instituição. Paralelamente, e não menos importante neste processo, se constituiu uma narrativa que não se dissocia da proposta da instituição que é relacional ao meio interno e externo do ecomuseu, como a exposição de imagens de aves da região e as trilhas ecológicas.

No Ecomuseu do Ribeirão da Ilha, a exposição se inicia no auditório da instituição e concentra toda a parte de textos explicativos que são apresentados pela museóloga da instituição. Esta profissional faz a apresentação da exposição, mostrando imagens e textos em monitor do auditório do ecomuseu. Nos módulos expositivos 'Casa do início do século $X X^{\prime}$ e 'Engenho de farinha', alguns objetos possuem etiqueta explicativa.Da mesma forma que o EDAF, o Ecomuseu do Ribeirão da Ilha se propõe a estabelecer uma relação com o seu território, patrimônio cultural e comunidade.

Nos dois ecomuseus analisados ocorre também a mediação que, como se constatou na pesquisa, pode ser considerada uma forma de representação da informação.No EDAF, a responsável é a Profa. Dra. Valda de Oliveira Fagundes (fundadora do EDAF) e no Ecomuseu do Ribeirão da Ilha, a Museóloga Cristina Maria Dallanora (neta do fundador). Conforme Gomes e Cazelli (2016, p.26) "a mediação em museus envolve potencialmente vários níveis de diálogo: entre o público e as exposições; entre os sujeitos e o saber; entre a arte, a ciência, a história e a sociedade".

O caráter de representação da informação que a mediação tem nestes casos é a forma como o visitante recebe a informação, pois em muitos casos as mediadoras conseguem contribuir com informações adicionais ao que se tem, o que ressalta sobre a ideia de Davallon (2007) ao mostrar que a mediação não serve apenas como um meio de acesso a uma mensagem ou informação, mas implica também na sua transformação.

$\mathrm{Na}$ relação do objeto de estudo com a Ciência da Informação, a mediação, neste caso aplicada à informação, pode ser um ponto de interconexão, especialmente ao considerar as reflexões de Barros, Café e 
Silva (2011). Ao discutir a mediação do conhecimento para o acesso à informação, as autoras afirmam que ainda existe uma complexidade na Ciência da Informação em relação à mediação. Isto porque é necessário que haja uma representação em primeiro e segundo nível, sendo que no primeiro nível existe a intenção em alguém comunicar seu conhecimento por algo escrito e em segundo nível, quando este conhecimento escrito carece de descrição, para que se torne um documento e possa ser organizado.

Ambas as situações de mediação podem ser presenciadas nos ecomuseus, afinal, como visto, a mediação na Museologia está presente por haver um terceiro elemento (mediador), entre público e informação, nestes casos Profa. Dra. Valda de Oliveira Fagundes (EDAF) e Cristina Maria Dallanora (Ecomuseu do Ribeirão da Ilha). O mesmo pode ser evidenciado quanto à mediação na área da $\mathrm{CI}$, onde o nível um (intenção em comunicar o conhecimento) está vinculado às ações de ambas as mediadoras.Já o nível dois (descrição do documento para ser organizado) está presente nas ações de documentação em museu e exposição, como apresentado anteriormente.

\section{0 ecomuseu a partir de seus representantes}

A metodologia da história oral foi escolhida para auxiliar na pesquisa de campo, possibilitando o acesso às informações pessoais daqueles que vivenciaram 0 processo de constituição dos Ecomuseus analisados.Conforme Alberti (1996) esta metodologia ajuda a entender a história a partir das representações dos que a vivenciaram. Na pesquisa, a história oral contribuiu para verificar as informações sobre a criação dos ecomuseus e a relação pessoal que cada um dos fundadores tem com a instituição. Para isto, optou-se pela entrevista temática, com roteiro aberto, contendo quatro tópicos a serem abordados: 1) contexto de criação; 2) equipe do ecomuseu; 3) ações desenvolvidas; e 4) relação do ecomuseu com a comunidade.

O tópico 1 (contexto de criação) foi utilizado para dar início a entrevista e deixar os entrevistados à vontade quanto à pesquisa e às perguntas. Também neste primeiro tema, foi enfatizado toda a trajetória de existência dos ecomuseus, o que é fundamental para verificar as motivações de criação das instituições e como ela está relacionada com a vida de seus fundadores.O tópico2 (equipe do ecomuseu) foi estabelecido para verificar se existiam profissionais da informação nos ecomuseus e como estes trabalhavam com a pesquisa, coleta, organização, recuperação e acesso à informação.O tópico 3 (ações desenvolvidas) foi necessário para identificar quais processos e ações os ecomuseus já desenvolveram ou desenvolvem, a fim de poder também identificar possíveis forma de representação da informação.Por fim, o tópico 4 
(relação do ecomuseu com a comunidade) foi posto para verificar se o conceito de ecomuseu, definido na Museologia, se aplica, de fato, às instituições pesquisadas.

Em entrevista, Fagundes (2017) contou que a criação do EDAF aconteceu no ano de 2007 como uma forma de homenagear seu falecido marido, Dr. Agobar Fagundes. Contudo, sua relação com objetos museais vem desde sua infância, quando colecionava louças e se interessada por galerias, antiquários e locais que tinham relação com arte e memória. Depois de casada com Dr. Agobar Fagundes, ambos começaram a montar uma coleção de ferramentas e utensílios antigos que ganhavam dos seus vizinhos e amigos.

Segundo Fagundes (2017), seu falecido esposo era amante da natureza e em sua casa de campo [atual sede do EDAF] fotografava animais e plantas. Com seu falecimento, ela quis fazer-lhe uma homenagem e criou o EDAF. Assim, nas palavras da entrevistada, a relação da instituição com a natureza é uma forma de rememorar a vivência antiga do Dr. Agobar Fagundes naquele ambiente. Nesse sentido, pode-se perceber que a constituição do Ecomuseu está intimamente ligada à memória de um tipo de valorização do mundo natural, tornando bastante tênue o limite entre o que é cultural e o que é natural na constituição deste Ecomuseu. Esta constatação, de certa forma, corrobora com o que foi discutido por Karpinski (2015, 2016 e 2018), para quem a dicotomia cultura/natureza influencia a definição das noções cultural e natural dos patrimônios naturais.

Quando indagada sobre a equipe da instituição,Fagundes (2017)explicou que esta é multidisciplinar e se constituía partir de distintos projetos e pesquisas. Segundo ela, qualquer pesquisador que queira utilizar o EDAF para fins acadêmicos e científicos é muito bem recebido, pois esta é uma das finalidades da instituição. Em sua narrativa, explicou também que o EDAF já possuiu biólogos, arquitetos e outros pesquisadores que auxiliaram a desenvolver trabalhos e pesquisas, principalmente voltados para meio ambiente e cultura. Entre essas ações, a entrevistada ressaltou as seguintes: exposição;trilhas ecológicas; projeto de observação de pássaros;uma biblioteca; participação em congressos de Ecomuseologia.

Por fim, sobre a relação entre o EDAF e a comunidade,Fagundes (2017) relatou que no inicio foi bem difícil, mas que aos poucos o cenário vem melhorando. Segundo ela, a comunidade a qual o EDAF tem como foco é a comunidade acadêmica e científica e, nesse sentido, a aproximação tem sido constante e produtiva. No entanto, quanto à inserção do EDAF junto à comunidade local, a entrevistada relatou algumas dificuldades explicando que quando a instituição foi criada[2007] muitas pessoas associaram 0 EDAF às instituições de controle e 
fiscalização ambiental.Isto se deve ao fato de que a comunidade local se encontra em área de proteção ambiental e, na época da criação do Ecomuseu, os populares acharam que sua função seria a de agir como denunciante de práticas culturais que envolviam a caça e estavam em desacordo com a lei. Além disso, explicou também que muitos não participam por causa de conflitos entre vizinhos e outros mal-entendidos que impedem a aproximação do Ecomuseu com a sociedade local.

Em suma, a diretora do EDAF relatou que existe ainda uma grande barreira a ser rompida para quehaja uma relação positiva com a comunidade local. No entanto, contou que outros bairros do município de Blumenau (SC), como o Progresso e o Garcia, estão começando a frequentar o EDAF. Além desses, outros grupos contribuem para adifusão da proposta da instituição, como os grupos de escoteiros que participam ativamente das atividades do ecomuseu.

Por fim, é importante também destacar uma frase que Fagundes (2017)expôs no final de sua entrevista, quando reforçou a necessidade pessoal de buscar capacitação constantemente. Segundo ela, é esse processo de aprendizado contínuo que pode fazê-la competente para tornar a proposta do EDAF compreensível a um número cada vez maior de pessoas. Nesse contexto ela expressou o seguinte: "[a capacitação] é fundamental para o processo de informar o visitante, pois trabalhar com informação é complicado". (Grifo dos autores).

A partir desta afirmação pode-se analisar o seguinte: a) trabalhar com informação seria complicado pela forma subjetiva que cada pessoa adquire informações; b) a forma como cada pessoa processa a informação e transforma em conhecimento é diferente; c) ao processar a informação em conhecimento o indivíduo também pode transferi-la para o meio externo influenciando a forma como a instituição estabelece sua narrativa; d) a informação pode se dar em totalidade ou em partes, podendo levar a compreensão daquilo que o EDAF propõe ou não.

No Ecomuseu do Ribeirão da Ilha a primeira entrevista foi concedida por Dallanora (2017), que relatou toda sua história com a instituição, vindo desde sua infância, pois o local onde o ecomuseu se encontra era a casa de praia da família. Ela disse que antes de existir o ecomuseu, o Ribeirão da Ilha possuía um museu sobre foldore e a cultura açoriana e pertencia a Sociedade dos Amigos Pro-desenvolvimento do Ribeirão da Ilha (SADPRI). Porém,com a dissolução da SADPRI, o antigo museu que existia no Ribeirão da Ilha mudou o nome para Ecomuseu do Ribeirão da Ilha, sendo que no ano de 2007 passou a ser gerido pela Associação pró Ribeirão da Ilha.

Quando falou sobre a equipe do ecomuseu em questão, Dallanora (2017) disse que é formada por ela [museóloga] e seu avô, e que em função disto as visitas devem ser agendadas bem como algumas 
atividades e ações que o ecomuseu desenvolve.Dessa forma, ela relatou que das ações que são desenvolvidas no ecomuseu a exposição necessita de medição, pois ela não fala por si só e que em alguns casos as atividades dependem da demanda de visitantes na instituição. Ressaltou ainda que a documentação do acervo foi feita porque houve a participação do edital Elisabete Anderle ${ }^{3}$ no ano de 2015, sendo o ecomuseu premiado.

Sobre a relação do Ecomuseu com a comunidade, a entrevistada afirmou que até o momento não houve um projeto específico para isto. Contudo, ressaltou que nos últimos tempos as escolas locais começaram a se aproximar da instituição. De acordo com seu diagnóstico, essa aproximação comunitária é prejudicada, principalmente, pelo escasso serviço de transporte público da região. Ela ainda destacou que a visitação poderia ser maior se o ecomuseu não fosse tão longe do centro de Florianópolis, onde a maior parte de museus e outros equipamentos culturais se encontram. Para a entrevistada, ambos os problemas, tanto a participação comunitária, quanto a maior visitação, se resolveriam caso o serviço de transporte público melhorasse, isso porque cerca de noventa por cento das visitas são de estudantes.

A segunda entrevista foi com Pereira (2017), fundador do Ecomuseu do Ribeirão da Ilha. Iniciou sua narrativa dizendo que o atual ecomuseu é consequência de um movimento pela criação de um museu temático de cultura açoriana na década de 1960. Essa iniciativa ganhou força em discussões departamentais da Universidade Federal de Santa Catarina, onde trabalhava como professor do departamento de Sociologia na época.Além disso, havia o interesse, por parte do poder público local, de criar um setor turístico no interior da municipalidade. De acordo com o entrevistado, o plano era beneficiar o Ribeirão da Ilha com projetos turísticos para evitar o êxodo que estava ocorrendo na localidade, onde muitas famílias deixavam o bairro histórico e tradicional para morar e trabalhar no centro da cidade.

Nesse sentido, Pereira (2017) também relatou que foi criada, na década de 1970, a Sociedade de Amigos pró Ribeirão da Ilha(SADPRI), cujo objetivo era o de desenvolver o turismo cultural no bairro. Nesse contexto, a ideia de criação de um museu no Ribeirão da Ilha ganhou força, mas, de acordo com o professor, não se sabia ao certo se o mesmo deveria ser uma instituição voltada ao folclore ou à história local. Ainda de acordo com ele,naquela época as pessoas da comunidade

30 Edital Elisabete Anderle de estímulo a Cultura, é um edital estadual de Santa Catarina, onde existem categorias para as premiações, incluindo a categoria "Prêmio Catarinense de Museus". Para maiores informações acessar: http://editalelisabeteanderle.cultura.sc/. 
queriam sua representatividade e, assim, no ano de 1971, foi criado o Museu Etnológico do Ribeirão da Ilha.

Mesmo falando sobre o contexto histórico anterior à própria criação do ecomuseu do Ribeirão da Ilha, Prof. Nereu do Vale Pereira adiantou dados importantes para a pesquisa, principalmente a relação do ecomuseu com a comunidade. Segundo ele, problemas nas relações interpessoais fizeram a SADPRI se extinguir. Pelo conteúdo da entrevista, pode-se dizer que esses fatores de conflito relacionados à SADPRI se projetaram também no ecomuseu, pois, segundo ele, houve um retraimento dos moradores locais e que hoje com algumas atividades pontuais, pelo menos as escolas estão voltando a ter ligação com o ecomuseu. Com isso, ele disse que as exposições do ecomuseu são sempre permanentes, pois há pouca equipe para pensar numa dinâmica e melhorar o que já tem, e há pouco espaço físico para a montagem das exposições.

Após o relato das três entrevistas verificam-se os seguintes pontos em comum nas duas instituições:

a) Os dois ecomuseus analisados se constituíram a partir de uma vontade pessoal;

b) A relação dos objetos com a informação se assemelham nos dois ecomuseus, se percebe uma forte ligação entre a mediação e a contextualização territorial. Isso reforça o entendimento de que a documentação em museu, exposição e a mediação são formas de representação da informação, esta última sendo uma forma alternativa para que o público tenha acesso à informação;

c) Nenhuma das duas instituições atua diretamente na comunidade local, o que, em termos conceituais, não obedeceria aos princípios da Ecomuseologia. No entanto, cabe ressaltar que, diante de outras características presentes em cada instituição, esse fato não pode descaracterizá-los enquanto ecomuseus. Pelo contrário, entende-se que suas especificidades pedem uma discussão e análise no campo da Museologia;

d) Também foi constatado que a relação das instituições com a informação se dá por meio dos objetos expostos, onde estes são analisados sobre dois pontos:

1) Representação de um passado; e

2) Curiosidade.

A representação de um passado traz alguma lembrança da infância ou da juventude para muitos adultos e idosos, principalmente pelo conteúdo memorialístico das exposições. Neste caso, uma casa, um moinho, um percurso externo pontuado por objetos representantes de um 
passado colonial, fazem com que o público se sinta incluído no discurso museológico e creditando sentido aos objetos museais. Assim, os objetos são portadores de informação e, como já explicava Otlet (1934), são documentos. Com relação à curiosidade, a exposição remete-se aos visitantes mais jovens, principalmente crianças e adolescentes, pois os instiga a saberem como determinado instrumento funcionava, como era o estilo de vida da comunidade no passado, etc.

É importante ressaltar que o fato de expor não existe por si só, mas que ele participa de um discurso. No EDAF, o discurso narrado pela exposição mostra a modificação do território pelo ser humano e a relação entre os povos indígenas e os colonizadores europeus. Enquanto no Ecomuseu do Ribeirão da Ilha o discurso é voltado para colonização açoriana na ilha de Santa Catarina, focando, principalmente, o modo de viver presente entre os séculos XVIII e XX.

Sendo assim, mesmo não observando um processo técnico que visa representar a informação, a representação da informação está presente na exposição, pois ela contextualiza os objetos expostos por meio da criação de uma narrativa em que a informação não se restringe a um processo.Pelo contrário, o conteúdo informacional se relaciona ao item exposto, à temática expositiva e ao feedback dos visitantes. A representação da informação no caso dos ecomuseus estudados ultrapassa as questões técnicas, pois estabelece a interação dos objetos com seu meio, seu contexto e sua relação com o público/usuário.

\section{Considerações finais}

Tendo em vista a categoria específica de museu adotado para a realização do trabalho, algumas considerações merecem destaque, principalmente no que se refere aos conceitos teóricos da área de Ciência da Informação e da Museologia.A Ciência da Informação podendo estabelecer novas temáticas de pesquisa e aplicação no âmbito da representação da informação em distintas unidades de informação, abrangendo neste escopo os museus e suas diversas categorias. Já para a Museologia faz-se necessário compreender as diferentes dinâmicas da ecomuseologia, os diversos locais onde ela é feita e trabalhada, e considerar conforme Rivière (1985) e Varine (1985) que é uma instituição em constante evolução.

No que tange à representação da informação, é necessário observar como os conceitos desta temática da Ciência da Informação, auxilia a compreensão de processos de organização da informação em outras áreas do conhecimento, buscando definir métodos e processos que se caracterizam como formas de representação da informação. Para esta pesquisa foi verificado três formas de representação da informação na Museologia, sendo: documentação em museus, exposição e a mediação. 
A documentação em museu enquanto forma de representação da informação se caracteriza por ser o processo de pesquisa, coleta, organização e recuperação da informação de objetos museais. Esta forma de representação da informação pode ser considerada de caráter técnico nas instituições, visando suprir uma necessidade de gestão e organização da informação em museus.

A exposição é a forma mais comum de acesso à informação nos museus, também tendo sua organização por meio do contexto e narrativa expositiva. O caráter de representação da informação na exposição se encontra na lógica do percurso, no modo como um texto auxilia na contextualização do objeto exposto, na experiência do público com o que é exposto.

Já a mediação é considerada uma forma de representação da informação pelas características citadas anteriormente, onde o mediador possibilita 0 acesso à informação a partir de direcionamentos, interpretações e explicações contextuais à exposição. Essa experiência, para além do resultado prático às intenções da instituição, traz o público para dentro do processo informacional, podendo constituir um feedback quase que instantâneo ao profissional.

De forma geral, todas essas formas de representação da informação estão correlacionadas. A documentação em museu fornece as informações para que uma exposição seja feita, contribuindo também com as informações passadas pela mediação. A exposição utiliza das informações da documentação e possibilita criar uma estética e uma narrativa sobre os objetos expostos. Por fim, a mediação possibilita uma troca maior de informação entre mediador e público, possibilitando ainda mais a construção do conhecimento por ambos.

Com relação à metodologia adotada, os dados obtidos pela história oral auxiliaram a reflexão sobre os ecomuseus como unidades de informação. Por meio desta metodologia foi possível coletar informações que não seriam encontradas de outra forma, senão pela narrativa dos entrevistados. A história oral é uma metodologia que pode ser mais utilizada na Ciência da Informação, auxiliando muitas vezes em informações faltantes, ajudando as pesquisas a eliminar lacunas que possam existir.

Por fim, a pesquisa ressalta a importância do caráter interdisciplinar da Ciência da Informação e da Museologia, principalmente pelo viés da representação da informação, mostrando as possibilidades de pesquisas conjuntas entre ambas, promovendo o desenvolvimento prático e teórico das duas áreas do conhecimento.

\section{Referências}


ALBERTI, V. O que documenta a fonte oral ?Possibilidades para além da construção do passado. Rio de Janeiro: CPDOC, 1996. Disponível em: http://bibliotecadigital.fgv.br/dspace/handle/10438/6767? show=full. Acesso em: 14 dez. 2017.

ARAúJo, C. A. Á. Arquivologia, biblioteconomia, museologia e ciência da informação: o diálogo possível. Brasília: Briquet de Lemos, 2014.

BARROS, C. M.; CAFÉ, L. M. A.; SILVA, E. L. Mediação do conhecimento para o acesso à informação: reflexão baseada em uma perspectiva sociológica da ciência da informação. Ciência da Informação, Brasília, v. 40, n. 3, p.468-477, set./dez. 2011. Disponível em: http://revista.ibict.br/ciinf/article/view/1302. Acesso em: 14 jan. 2018

BOTTALLO, M. Os museus tradicionais na sociedade contemporânea: uma revisão. Revista do Museu de Arqueologia e Etnologia, São Paulo, n. 5, p. 283-287, 18 dez. 1995. Disponível em: http://www.revistas.usp.br/revmae/article/view/109242/107713. Acesso em: 28 nov. 2018

BRASCHER, M.; CAFE, L. Organização da informação ou organização do conhecimento?In: ENCONTRO NACIONAL DE PESQUISA EM CIÊNCIA DA INFORMAÇÃO, 9., 2008, São Paulo.[Anais...] Brasília: AssociaçãoNacional de Pesquisa e Pós-Graduação em Ciência da Informação, 2008. Disponível em:

http://enancib2013.ufsc.br/index.php/enancib2013/XIVenancib/paper/vie w/155/147. Acesso em: 10 jun. 2016.

BRULON, B. A INVENÇÃO DO ECOMUSEU: O Caso do Écomusée Du Creusot Montceau-Les-Mines e a Prática da Museologia Experimental. Mana, Rio de Janeiro, v. 21, n. 2, p.267-295, ago. 2015. Disponível em: http://www.scielo.br/scielo.php?script=sci arttext\&pid=S010493132015000200267. Acesso em: 23 out. 2017.

CHAGAS, M. S. Memória e poder: contribuição para a teoria e a prática dos ecomuseus. In: ENCONTRO INTERNACIONAL DE ECOMUSEUS, 2.,2000, Rio de janeiro.[Anais...] Rio de Janeiro: Núcleo de Orientação e pesquisa Histórica (NOPH), 2000. Disponível em:

https://pt.scribd.com/document/275598704/Memoria-e-podercontribuicao-para-a-teoria-e-a-pratica-nos-ecomuseus. Acesso em: 22 jan. 2018.

CHAGAS, M.; ABREU, R. (Org.).Memória e patrimônio. Ensaios contemporâneos.2.ed. Rio de Janeiro, Lamparina, 2009. 
CHOAY, F. A alegoria do patrimônio. 5.ed. São Paulo: Estação Liberdade, 2014.

CRUZ NETO, O. O trabalho de campo como descoberta e criação. In: MINAYO, M. C. S. Pesquisa Social: teoria, método e criatividade. 21. ed. Petrópolis: Vozes, 2002. p. 51-66.

CUNHA, M. B. Exposições Museológicas como estratégias de comunicação.Seminário: Exposições Museológicas como estratégias de comunicação. Lisboa: Universidade Lusófona de Humanidades e Tecnologia, 2005.

DALLANORA, C.M. Cristina Maria Dallanora: depoimento [maio 2017]. Entrevistador: L. H. Lemos. Florianópolis: Ecomuseu do Ribeirão da Ilha, 2017. 1 gravação digital (21 min). Entrevista concedida para a dissertação "A Representação da Informação em Ecomuseus".

DAVALLON, J. A mediação: a comunicação em processo? Revista virtual Prisma de Ciências da Informação e Comunicação, Porto, n. 4, p. 336.jun. 2007.Disponível em:

http://ojs.letras.up.pt/index.php/prismacom/article/view/2100/3046.

Acesso em: 14 maio 2020.

ECOMUSEU DO RIBEIRÃO DA ILHA. Casa em estilo açoriano.2011a. 1 imagem digital.Disponível em: https://ecomuseuribeirao.wordpress.com/. Acesso em: 19 jan. 2018.

ECOMUSEU DO RIBEIRÃO DA ILHA. Engenho de farinha de mandioca.2011b. 1 imagem digital.Disponível em: https://ecomuseuribeirao.wordpress.com/. Acesso em: 19 jan. 2018.

ECOMUSEU DR. AGOBAR FAGUNDES. Exposição de longa duração. 2016a. 1 imagem digital.Disponível em:

https://www.ecomuseuagobarfagundes.com.br/o-ecomuseu/. Acesso em: 22ago. 2018.

ECOMUSEU DR. AGOBAR FAGUNDES. Exposição de longa duração.2016b. 1 imagem digital.Disponível em:

https://www.ecomuseuagobarfagundes.com.br/o-ecomuseu/. Acesso em: 22 ago. 2018.

FAGUNDES, V.O. Valda de Oliveira Fagundes: depoimento [maio 2017]. Entrevistador: L. H. Lemos. Florianópolis: Ecomuseu Dr. Agobar Fagundes, 2017. 1 gravação digital (44 min).Entrevista concedida para a dissertação "A Representação da Informação em Ecomuseus". 
FOGL, J. Relations of the concepts 'information' and 'knowledge'.

International Fórum on Information and Documentation, The Hague, v.4, n.1, p. 21-24, 1979.

GIL, A. C. Como elaborar projetos de pesquisa. 4. ed. São Paulo: Atlas, 2010.

GOMES, I.; CAZELLI, S. Formação de Mediadores em Museus de Ciência:

Saberes e Práticas. Ensaio Pesquisa em Educação em Ciências. v. 18, n. 1, p.23-46, 15 mar. 2016. Disponível em:

http://www.scielo.br/pdf/epec/2016nahead/1983-2117-epec

2016180102.pdf. Acesso em: 21 ago. 2018.

KARPINSKI, C. Informação, memória e patrimônio natural. In: ENCONTRO NACIONAL DE PESQUISA EM CIÊNCIA DA INFORMAÇÃO, 17., 2016.

Salvador. [Anais...]Salvador: PPGCI/UFBA, 2015.

Disponívelem:http://www.ufpb.br/evento/lti/ocs/index.php/enancib2016/e nancib2016/paper/viewFile/3658/2378. Acesso em: 20 maio 2018.

KARPINSKI, C. Patrimônio natural e arquivo: experiência de pesquisa sobre as cataratas do Iguaçu. In: ENCONTRO NACIONAL DE PESQUISA EM CIÊNCIA DA INFORMAÇÃO, 16., 2015. João Pessoa. [Anais...]]João Pessoa: PPGCI/UFPB, 2015.

Disponívelem: http://www.ufpb.br/evento/lti/ocs/index.php/enancib2015/e nancib2015/paper/viewFile/2816/1227. Acesso em: 20 maio 2018.

KARPINSKI, C. Patrimônio natural, documentação e pesquisa.Trans Informação, Campinas, v.30, n.3, p.314-323. Disponível em:

http://www.scielo.br/scielo.php?script=sci arttext\&pid=S0103-

37862018000300314\&lng=en\&nrm=iso. Acesso em: 14 maio 2020.

KARPINSKI, C. ; MONTYSUMA, M. F. F. Memória e história oral. Indaial: UNIASSELVI, 2009.

LAKATOS, E. M.; MARCONI, M. A. Metodologia do trabalho científico. São Paulo: Atlas, 2007.

LEMOS, L. H. ; KARPINSKI, C. Representação da informação e ecomuseologia a partir de pesquisa bibliográfica. Museologia e Patrimônio, Rio de Janeiro, v.12, n.2, 2019.Disponível em:

http://revistamuseologiaepatrimonio.mast.br/index.php/ppgpmus/article/ view/712/686. Acesso em: 14 maio 2020.

LIRA, B. C. O passo a passo do trabalho científico. 2 ed. Petrópolis, RJ: Vozes, 2014. 
MENSCH, P. Museology and the object as data carrier.In: . Object, museum, Museology, an eternal triangle. Leiden: Reinwardt Academy. Reinward tCahiers, 1992.Disponível em: http://www.muuseum.ee/uploads/files/mensch12.htm. Acesso em: 24 out. 2017.

MONTYSUMA, M. Um encontro com as fontes em História Oral. Estudos Ibero-americanos, Porto Alegre, v. 23, n. 1, p. 117-125, 2006. Disponível em:

http://revistaseletronicas.pucrs.br/ojs/index.php/iberoamericana/article/vi ew/1304/1009. Acesso em: 29 abr. 2020.

OTLET, Paul. Traité de Documentation: Le livresurlelivre. Bruxelles: Mundaneum, 1934.

PERELMETTER, D. ; ANTONACCI, M. A. (Org.). Ética e história oral. São Paulo: EDUC, 1997.

PORTELLI, A. Tentando aprender um pouquinho: algumas reflexões sobre a ética na História Oral. Projeto História, São Paulo, v. 15, p.13-49, 1997. Disponível em: https://revistas.pucsp.br/revph/article/view/11215/8223. Acesso em: 29 abr. 2020.

PEREIRA, N.V. Nereudo Vale Pereira: depoimento [mai.2017].

Entrevistador: L. H. Lemos. Florianópolis: Ecomuseu do Ribeirão da Ilha, 2017. 1 gravação digital (38 min). Entrevista concedida para a dissertação A Representação da Informação em Ecomuseus.

POULOT, D. Museu e museologia.Trad. Guilherme João de Freitas Teixeira. Belo Horizonte: Autêntica, 2013.

POZZI, P. La ética, la historia oral y sus consecuencias. História oral, Rio de Janeiro, v.17, n.2, p.47-67, 2014.Disponível em:

http://revista.historiaoral.org.br/index.php?journal =rho\&page $=$ issue\&op $=$ view\&path\%5B\%5D=34\&path\%5B\%5D=showToc. Acesso em: 14 maio 2020.

QUEROL, L. S. Para uma gramática museológica do (re)conhecimento: ideias e conceitos em torno do inventário participado. Sociologia: Revista da Faculdade de Letras da Universidade do Porto, Porto, v. 25, n. 0, p.165-188, jan. 2013. Disponível em:

http://www.scielo.mec.pt/scielo.php?script $=$ sci arttext\&pid $=$ S087234192013000100009. Acesso em: 23 out. 2017.

RIVIÈRE, G. H. Definición evolutiva del ecomuseo. Museum, Paris, v. 37, n. 148, p.182-183, 1985.Trimestral.Disponível em: 
https://unesdoc.unesco.org/ark:/48223/pf0000068366 spa. Acesso em: 14 maio 2020.

RONCAYOLO, M. Território. In: ENCICLOPÉDIA Einaudi, v. 8 (Região). Lisboa: IN/CM, 1986, pp. 262-290.

SCHEINER, T. C. Repensando o museu integral: do conceito às práticas. Boletim Museu Paraense Emílio Goeldi, Belém , v.7, n. 1, p. 15-30, Abr. 2012. Disponível em:

https://www.scielo.br/pdf/bgoeldi/v7n1/a03v7n1.Acesso em:14 maio 2020.

TRIVIÑOS, A. N. S. Introdução à pesquisa em ciências sociais: a pesquisa qualitativa em educação. São Paulo: Atlas, 1987.

VARINE, H. El ecomuseo, más allá de la palabra. Museum, Paris, v. 37, n. 148, p.185, 1985.Trimestral.Disponível em:

https://unesdoc.unesco.org/ark:/48223/pf0000068367 spa. Acesso em: 14 maio 2020. 